\title{
Literature Review of Structured Entities
}

\author{
Dan Luo \\ School of Management, Jinan University, Guangzhou, China \\ Email:jnuld729@foxmail.com
}

How to cite this paper: Luo, D. (2020) Literature Review of Structured Entities. American Journal of Industrial and Business Management, 10, 522-530. https://doi.org/10.4236/ajibm.2020.103035

Received: February 5, 2020

Accepted: March 1, 2020

Published: March 4, 2020

Copyright $\odot 2020$ by author(s) and Scientific Research Publishing Inc. This work is licensed under the Creative Commons Attribution International License (CC BY 4.0).

http://creativecommons.org/licenses/by/4.0/

\begin{abstract}
The "Accounting Standards for Business Enterprises No. 41-Disclosure of Rights and Interests in Other Entities" promulgated in China in 2014 proposed the concept of "structured entities", and the 2014 revised "Enterprise Accounting Standards No. 33-Consolidated Financial Statements" made clear a single control-based consolidation model for all entities, and stated that "structured entities" controlled by the parent company should be included in the scope of consolidation of the company's financial statements. The introduction of the concept of "structured entities" and changes in related standards have placed new requirements on accounting theory researchers and practical staff. The article reviews related research on what is a "structured entities" and its similar special purpose entities and variable interest entities.
\end{abstract}

\section{Keywords}

Structured Entities, Special Purpose Entities, Literature Review

\section{Introduction}

In 2014, the Ministry of Finance issued a series of accounting standards based on the 38 specific accounting standards of the original accounting standards, which indicates that China's accounting standards are basically complete and converge to international accounting standards. Among them, Accounting Standards for Business Enterprises No. 41-"Disclosure of Interests in Subjects" proposes an important concept-structured entities, and defines them as "subjects that are not designed with voting or similar rights as the determining factor in determining their controlling party". The concept of structured entities first appeared in IFRS12, which was issued in 2011, and its essence is a derivative of special purpose entities and variable interest entities. The innovation of structured entities as financial instruments plays an increasingly important role in revitalizing existing funds and improving corporate financing efficiency. At present, the 
number of structured entities in China has shown a steady growth trend. Structured entities were established between 2014 and 2017. The number of companies that are: $76,87,135,152$, is bound to appear more and more structured entities in the future.

At the same time, the "Accounting Standards for Business Enterprises No. 33-Consolidated Financial Statements" revised by the Ministry of Finance in 2014 stated that control is the determining standard for the consolidation of all types of entities and clearly states that the structured entities controlled by the parent company should be included in the consolidated statements. The new standard also redefines "control", that is, "investors have the power over the investee, enjoy variable returns by participating in the investee's related activities, and have the ability to use the power to influence the investee of its return amount". This definition indicates that the new standard places more emphasis on substantive control, but CAS33 (2014) does not make clear the standard of substantive control. This makes the judgment of "substantial control" more principle-oriented. Relying heavily on professional judgment, on the one hand, it brings difficulties to practitioners, and on the other hand, it also gives "high-level" practitioners to take opportunistic actions by using loopholes in the rules.

\section{Literature Review of Structured Entities}

\subsection{Special Purpose Entity}

The special purpose entity originated in the United States in the 1970s and developed rapidly with the wave of asset securitization in the 1990s. SIC12 defines it as "an entity established to complete a limited scope of activities with a clear purpose". The special purpose entity was originally a financial instrument used for tax planning, saving financing costs, and diversifying or transferring risks, but there were loopholes in the accounting standards at that time. Financial instruments were excluded from the financial statements because they did not meet the criteria for inclusion in consolidated statements. In addition, some savvy practitioners take advantage of the loopholes in the standards, such as transferring non-performing assets or liabilities through the establishment of special purpose entities, to achieve fraud in financial statements. The most typical case is the sensational Enron incident. According to relevant US accounting standards, when a third-party investor's equity investment in a special purpose entity is greater than or equal to $3 \%$, it is not necessary to include the special purpose entity in the consolidated statement. Enron It is the use of loopholes in this standard to set up hundreds of special-purpose entities. High-price transfers allow assets to be sold to the associated special-purpose entities to achieve false profits and disguise their true financial status.

Since then, the academic community has begun to focus on special purpose entities, but most of the research on special purpose entities is normative research, and empirical research is rare. Feng et al. (2009) found that US compa- 
nies using special purpose entities increased by a factor of two and a half from 1997 to 2004 . At the same time, the number of special purpose entities increases with financial reporting incentives and economic and tax incentives, but strong corporate governance tends to reduce the use of special purpose entities. Finally, the article finds that there is a positive correlation between the special purpose entities set up with financial reporting as the motivation and earnings management, and there is no correlation between the special purpose entities set up for other purposes and earnings management. Amoruso \& Duchac (2014) believes that special purpose entities have become a vital part of the 21 st century financial system, providing the necessary structure for securitized mortgages. Although these entities can effectively isolate the risk of bankruptcy for companies, they also created a shadow banking system that exposed the US economy to excessive risks. Demere et al. (2015) found through path analysis that special purpose entities contribute to higher levels of specific tax incentives. The analysis of 10284 companies using SPE shows that SPE promotes total incremental cash of approximately $\$ 84.2$ billion Tax deductions, which accounted for approximately $2 \%$ of US federal corporate taxes during 1997-2011. Research by Kim et al. (2017) show that companies with special purpose entities face adverse terms in the terms of loan contracts, such as their tendency to pay higher loan rates, incidental mortgage requirements, and restrictive terms. This is mainly because the executives of such companies can more easily use special purpose entities to manipulate surpluses and conceal losses, thus making information risks higher. In addition, the article finds that companies with special purpose entities are more likely to restate their financial statements

\subsection{Variable Interest Entity}

With the occurrence of the Enron incident, market regulators began to realize that there were significant loopholes in the consolidation of special purpose entities, and the first systematic guide on special purpose entities was published in 2003-FAS 140 No. 46 (FIN46) And the revised FIN46 (R), the newly issued FIN46 (R) first proposed the concept of "variable interest entity" to replace the "special purpose entity". However, the above document does not clearly define a variable interest entity, but instead lists its characteristics: without additional subsidiary financial support, the risky equity investment is insufficient to meet the needs of its operating activities. Variable interest entities are generally referred to as "contractual control" in China, which generally refers to the separation of a listed company registered overseas from its entity operating in the country. The listed company is an overseas company, and the overseas company controls the domestic business through an agreement. Entities. In this structure, business entities are called VIEs, or "variable interest entities.” In 2000, Sina first successfully listed overseas through the VIE structure. So far, listing through VIE is known as the most commonly used method for companies in China's emerging industries. An important step in setting up a VIE structure is to set up off- 
shore companies in tax havens. Therefore, when referring to variable interest entities, offshore companies must be mentioned. Existing research shows that the establishment of offshore companies can achieve the purpose of effective tax avoidance. Dyreng and Lindsey (2009) research found that if American companies set up companies in the "tax haven" area, their overall tax rate would be $1.5 \%$ lower. Since setting up an offshore company can achieve the purpose of effective tax avoidance, what kind of company is more likely to set up an offshore company? Research by Desai et al. (2006) show that companies with larger scale, higher degree of internationalization, more active inter-company transactions, and more R \& D-intensive companies tend to set up offshore companies.

\subsection{Structured Entities}

The concept of a structured entities first appeared in IFRS12, which was issued in 2013. CAS41, issued in 2014, defined structured entities as "designed without determining voting rights or similar rights as a determining factor when determining their controlling party." In general, structured entities carry out business activities within the scope of the contract, and voting rights or similar rights are only related to administrative management matters, mainly including some securitization tools, wealth management products, investment funds, etc. At the same time, CAS41 (2014) shows that usually structured entities include the following characteristics: first, the scope of business activities is limited; second, there is a specific and relatively single purpose; third, when equity is not sufficient to support its business activities, it must rely on For other sub-financial support; Fourth, financing by issuing different grades of securities to investors. At the same time, CAS33 (2014) pointed out that control is the determining standard for the consolidation of all types of entities, and clearly stated that the structured entities controlled by the parent company should be included in the consolidated statement. Enterprises not only need to disclose the structured entities included in the consolidated statements, but also the size of the structured entities that have not been included in the consolidated statements and the reasons why they have not been included in the consolidated statements.

Most of the current domestic researches on structured subjects are normative articles. Zhang (2015) explained the connotation of the above three types of subjects by introducing the evolution process from special purpose subjects, variable interest entities to structured subjects, and the background and reasons for related concepts, the content of relevant accounting standards, and typical cases. And analyze its definition and disclosure rules, so that practical operators can grasp the concept differences and make practical judgments. Zeng (2016) believes that according to the definition of a structured entity, another entity's right to control it is to control, obtain variable returns by participating in related activities, and at the same time, can influence its return amount through the power of ownership. The detailed judgment of control determines whether the structured entity belongs to the scope of consolidation, and determines that the 
merger process should be comprehensively combined with factors such as its design method and purpose, related activities, and risk exposure of variable returns. The actual controlling party of the structured entity is: it is the party that has the ability to have the greatest impact on variable returns. Liu (2016) believes that for structured entities that are included in the consolidated statement but have no contractual agreement, the meaning of "financial support" should be clarified, such as providing funds to the structured entity for free, purchasing and issuing bonds, exempting debt, or unfair transactions. Structured entities have various forms of expression. The business they perform includes financing, but may not have the organizational form of a financial institution, for example, some are for the purpose of leasing business, some are for the purpose of changing the asset structure, and some are for the purpose of quickly recovering funds by transferring assets. Zhao (2017) analyzed the concepts and characteristics of structured subjects and investment subjects, and concluded that the structure of structured subjects is flexible and the risks are relatively large. Yang and Yan (2017) selected samples from 1679 listed companies for research, and found that the sample companies adopting the new standard have better disclosure of structured entities, but some companies still have not disclosed whether they have a structure included in the scope of consolidation Or not disclose whether financial support is provided to structured entities that are not included in the scope of consolidation.

\subsection{Asset Securitization}

In the process of asset securitization, the establishment of special purpose entities and variable interest entities is a key step. It can be seen that asset securitization and structured entities have an inseparable relationship. The so-called asset securitization is the process of repackaging the cash flows that can be generated by the underlying assets into asset-backed securities. A key step in the asset securitization process is the establishment of SPE, VIE, or SE to achieve risk isolation. China's asset securitization started relatively late and is still in the stage of development and improvement. Foreign asset securitization started earlier, and research on asset securitization is more abundant. At home and abroad, researches on the impact of asset securitization on the micro level are mainly banks and enterprises. Because financial institutions play an important role in asset securitization, a large amount of literature has studied the relationship between banks and asset securitization.

Affinito \& Tagliaferri (2010) studied the reasons for commercial banks' asset securitization. The research shows that banks with lower capitalization, lower profitability, lower liquidity, and more non-performing loans are more likely to go larger scale and earlier securitization, Jiangli \& Pritsker (2008). We used data from US bank mortgage securitization from 2001 to 2007 to evaluate the impact of mortgages and other forms of asset securitization on bankruptcy risk, profitability, and leverage. Studies show that mortgage securitization can not only im- 
prove banks' profitability, optimize leverage ratios, but also reduce the risk exposures that banks face. Beccalli et al. (2015) analyzed the relationship between the procyclical effect of leverage in the US banking industry and asset securitization. Studies have shown that the level of leverage and profit of banks performing asset securitization are procyclical. Albertazzi et al. (2015) research shows that the default probability of asset-backed securitization mortgages is lower than that of non-asset-backed mortgages because banks do not sell products because of their own reputation. Domestic research on the relationship between asset securitization and banks is also very rich. Liu and Li (2013) studied the impact of asset securitization on the bank's asset liquidity, profitability, and risk level through financial data from 38 US banks for the 25 quarters of 2005-2011. The results show that the relationship between asset securitization and profit level and risk level is different due to the size of the bank's assets. The larger the asset size, the higher the level of asset securitization, the lower the bank's profit level and the higher the risk level; The smaller the asset scale, the higher the level of asset securitization, the higher the bank's profitability and the lower the risk level. Wang and Zou (2016) selected the financial data of 16 banks in China from the 19th quarter of 2010 to 2014 to study the impact of bank credit asset securitization on the stability of bank operations. The results show that banks reduce the risk level of credit asset securities while it can also improve the level of profitability, thereby achieving stable development of the bank.

As for the connection between asset securitization and non-financial, asset securities show different advantages and disadvantages. Dechow \& Shakespeare (2009) believes that due to the discretion of the enterprise in the accounting treatment of asset securitization, the enterprise may adopt the act of manipulating earnings and whitewashing statements. The research results of Nadaul \& Weisbach (2012) show that asset securitization can reduce the financing cost of enterprises, and securitization will be $11-20$ points lower than non-securitized financing interest rates, thereby reducing financial costs of enterprises. At the same time, research by Lemmon et al. (2014) shows that asset securitization provides a new means of financing for non-financial companies. The financing cost of the enterprise. Asset securitization can not only reduce financing costs, but also reduce tax burden. Research by Han et al. (2015) shows that banks with abundant loan opportunities but limited deposit market power are more likely to securitize to reduce their tax burden. Domestic literature on non-financial companies as the research object has little literature on asset securitization. Zhang (2009) showed that asset securitization is the third mainstream financing method alongside debt financing and equity financing. The article mainly studies receivables. The main risks faced by asset securitization and pricing issues. Zhou (2012) analyzed four aspects of the significance of asset securitization: first, broadening financing channels and optimizing capital structure; second, enhancing asset liquidity; third, reducing corporate financing costs; fourth, reduce the risk assets of the enterprise. On the empirical side, Xiao and Chen (2016) se- 
lected data of 33 A-share companies from 2007 to 2014 and studied the relationship between asset securitization and financial characteristics. The research results show that the smaller the company, the more current liabilities it Tend to securitize assets.

\section{Conclusion}

This article mainly reviews existing research through three parts: structured subjects, asset securitization, and opportunistic behavior. According to the literature review, we can see that structured subjects have evolved from special purpose entities and variable interest entities, but still there are differences from the latter two, mainly in terms of definition and disclosure requirements. At the same time, most of the domestic research on structured subjects is still in the normative research, and the empirical research is still relatively small. The main research is to analyze the differences between structured subjects and special purpose entities and variable interest entities, as well as their practical handling. Problems should be noted. Foreign countries conduct empirical research on the motivation for the establishment of special-purpose entities and variable-interest entities and the economic effects brought about by them, but there are certain differences between structured subjects and the two. At the same time, due to the inseparable relationship between structured entities and asset securitization, research on asset securitization has focused on the utility brought by asset securitization. On the one hand, asset securitization can optimize the capital structure, reduce corporate financing costs, enhance asset liquidity, and improve profitability. On the other hand, in the process of asset securitization, there will be a company's behavior of manipulating earnings and whitewashing statements, which will bring negative effects. The research on management opportunism mainly focuses on influencing factors. The factors affecting management opportunism include: the company's shareholding structure, the sensitivity of salary performance, the size of management power, and the supervision of the government and competent authorities.

\section{Future Research Outlook}

Existing domestic literature on the study of structured subjects is still limited to normative research. Existing foreign literatures have conducted empirical research on the motivation for the establishment of special purpose entities, but structured subjects, special purpose entities, and variable interest entities exist certain difference. The research in this article is mainly to sort out the related research on structured subjects, in order to better understand the current status of research on structured subjects in academia. This article is still normative research. In the future, domestic research on structured subjects should focus on empirical research on the reasons for its establishment and the economic impact it may bring, in order to better understand the structured subjects and better prevent their potential in practice, and risks to promote the healthy development 
of the capital market.

\section{Conflicts of Interest}

The author declares no conflicts of interest regarding the publication of this paper.

\section{References}

Affinito, M., \& Tagliaferri, E. (2010). Why Do (Or Did?) Banks Securitize Their Loans? Evidence from Italy. Journal of Financial Stability, 6, 189-202.

https://doi.org/10.1016/j.jfs.2010.01.004

Albertazzi, U., Eramo, G., Gambacorat, L., \& Salleo, C. (2015). Asymmetric Information in Securitization: An Empirical Assessment. Journal of Monetary Economics, 71, 33-49. https://doi.org/10.1016/j.jmoneco.2014.11.002

Amoruso, A. J., \& Duchac, J. (2014). Special Purpose Entities and the Shadow Banking System: The Backbone of the 2008 Financial Crisis. Academy of Accounting and Financial Studies Journal, 18, 107.

Beccalli, E., Boitani, A., \& Giuliantonio, S. (2015). Leverage Pro-Cyclicality and Securitization in US Banking. Journal of Financial Intermediation, 24, 200-230. https://doi.org/10.1016/j.jfi.2014.04.005

Dechow, P., \& Shakespeare, C. (2009). Do Managers Time Securitization Transactions to Obtain Accounting Benefits? The Accounting Review, 84, 99-132.

https://doi.org/10.2308/accr.2009.84.1.99

Demere, P., Donohoe, M. P., \& Lisowsky, P. (2015). The Economic Effects of Special Purpose Entities on Corporate Tax Avoidance. Rochester, NY: Social Science Electronic Publishing. https://doi.org/10.2139/ssrn.2557752

Desai, M., Foley, F., \& Hines, J. (2006). The Demand for Tax Haven Operation. Journal of Public Economics, 90, 513-531. https://doi.org/10.1016/j.jpubeco.2005.04.004

Dyreng, S., \& Lindsey, B. (2009). Using Financial Accounting Data to Examine the Effect of Foreign Operations Located in Tax Havens and Other Countries on U.S. Multinational Firms' Tax Rates. Journal of Accounting Research, 47, 1283-1316.

https://www.jstor.org/stable/40389226 https://doi.org/10.1111/j.1475-679X.2009.00346.x

Feng, M., Gramlich, J., \& Gupta, S. (2009). Special Purpose Vehicles: Empirical Evidence on Determinants and Earnings Management. The Accounting Review, 84, 1833-1876. https://doi.org/10.2308/accr.2009.84.6.1833

Han, J., Park, K., \& Pennacchi, G. (2015). Corporate Taxes and Securitization. Journal of Finance, 70, 1287-1321. https://doi.org/10.1111/jofi.12157

Jiangli, W., \& Pritsker, M. G. (2008). The Impacts of Securitization on US Bank Holding Companies. SSRN Electronic Journal, 3, 377-393. https://doi.org/10.2139/ssrn.1102284

Kim, J., Song, B., \& Wang, Z. (2017). Special Purpose Vehicles and Bank Loan Contracting. Journal of Banking and Finance, 74, 133-152. https://doi.org/10.1016/j.jbankfin.2016.10.006

Lemmon, M., Liu, L. X., Mao, M. Q., \& Nini, G. (2014). Securitization and Capital Structure in Nonfinancial Firms. Journal of Finance, 32, 371-387.

Liu, J. H. (2016). Research on Relevant Issues in the Process of Structured Subject Information Disclosure. Journal of Pingdingshan University, 2. 
Liu, Q. L., \& Li, F. F. (2013). Asset Securitization and Bank Asset Liquidity, Profitability and Risk Level. Financial Forum, 18, 35-44.

Nadauld, T. D., \& Weisbach, M. S. (2012). Did Securitization Affect the Cost of Corporate Debt? Journal of Financial Economics, 105, 332-352. https://doi.org/10.1016/j.jfineco.2012.03.002

Wang, J. S., \& Zou, D. Z. (2016). The Impact of Credit Asset Securitization on the Stable Operation of Banking Industry. Financial Theory and Practice, No. 7, 57-61.

Xiao, D. S., \& Chen, Y. (2016). Research on the Relationship between Corporate Asset Securitization and Financial Characteristics. Journal of Nanhua University (Social Science Edition), 17, 58-62.

Yang, Q., \& Yan, H. (2017). On the Improvement of the Information Disclosure of the Merger Scope-Based on the Statistical Analysis of the Annual Report Samples of China's A-Share Listed Companies. China Accounting Monthly, 16, 16-22.

Zeng, D. S. (2016). Research on Accounting Issues for Structured Entity. Finance and Economics (Academic Edition), 7, 229-243.

Zhang, H. T. (2015). The Evolution Process from SPE, VIE to SE. Modernization of Shopping Malls, 14, 180-181.

Zhang, W. Q. (2009). On the Risk and Pricing of Securitization of Accounts Receivable Assets of Entity Enterprises. Financial Research, 5, 194-206.

Zhao, L. W. (2017). Discrimination of Structured Subjects and Investment Subjects. Learning of Finance and Accounting, No. 5, $109+126$.

Zhou, R. (2012). Practical Thoughts on Enterprise Asset Securitization. Contemporary Economy, 12, 146-147. 